\title{
Prognostic Significance of Systematic Lymphadenectomy as Part of Primary Debulking Surgery in Patients with Ovarian Cancer
}

\author{
Saied Hosny Bendary ${ }^{1}$, Mohamed Esmat Abd Elghany ${ }^{1}$, \\ Salama Saad Abd Al Latif ${ }^{2}$, \& Mohamed Ahmed Abd Elrauf Attia ${ }^{1 *}$ \\ ${ }^{1}$ Surgical Oncology Department, ${ }^{2}$ Clinical Pathology Department, Faculty of Medicine, Al Azhar \\ University \\ *Corresponding Author: Mohamed Ahmed Abd Elrauf Attia, Phone No.: (+2) 01008382152, E-mail: \\ dr_mohamed_abdelrauf@yahoo.com
}

\begin{abstract}
Background: worldwide, ovarian cancer is diagnosed in more than 200,000 women yearly and accounts for over 125,000 deaths. Unfortunately, about $70 \%$ of cases are diagnosed in an advancedstage with evidence of upper abdominal spread in approximately half of these.

Aim of the Work: was to review the surgical management of female patients with ovarian cancer including intraperitoneal complete cytoreduction and systematic lymphadenectomy to show prognosis, post operative morbidities, recurrence and follow up.

Patients and Methods: this study was conducted at Al-Azhar university hospitals and El Agousa police hospital - Ministry of interior - on 20 female patients who suffered from different stages of epithelial ovarian cancer with stage II, none bulky stage III, and only One patient with bilateral ovarian cancer stage Ic.

Results: This is study conducted on female patients with ovarian cancer the mean age of the studied patients was 51.35 years ranging from 37-64 years. 55\% of patients represented with abdominal distension, 50\% had abdominal pain, 40\% abdominal discomfort,15\% had abnormal bleeding ,65\% had nonspecific GIT manifestation ,20\% had urinary symptoms and $10 \%$ had back pain.

Conclusion: Although the relationship between the retroperitoneal spread of lymph nodes and patient prognosis has been demonstrated in several studies. lymphadenectomy, as a routine treatment procedure in ovarian cancer, remains controversial. Moreover, systematic lymphadenectomy often prolongs operation times, which may result in additional surgical complications such as lymphocele, lymphatic obstruction, lymphocysts and lymphedema, however these complications may be alleviated, and better outcome occurred by proper intra operative and post operative management by expert gynecological oncologist involvement and leveraging adequate instruments, which can eventually improve survival.
\end{abstract}

Keywords: Systematic Lymphadenectomy - Ovarian Cancer - Primary Debulking Surgery.

\section{INTRODUCTION}

Ovarian cancer is the second most lethal gynecologic malignancy worldwide, and the majority of women present with an advanced stage of the disease. Primary cytoreductive surgery followed by platinum and taxane combination chemotherapy is the standard treatment of this disease ${ }^{(\mathbf{1})}$.

Peritoneal implantation by exfoliation of tumor cells and lymphatic dissemination are common routes of spread in ovarian cancer, so cytoreductive surgery should include both intraperitoneal and retroperitoneal surgical procedures. In recent years, there has been growing recognition that radical pelvic and abdominal cytoreductive procedures are associated with a favorable prognosis in patients with advanced ovarian cancer, and a number of studies have demonstrated the importance of maximal cytoreductive surgical effort minimizing residual disease ${ }^{(2)}$.

However, the role of lymphadenectomy as part of maximal debulking surgery is still controversial. Some investigators have reported that systematic (complete) lymphadenectomy removes bulky or microscopic nodal diseases and might result in the improvement of survival in patients with advanced ovarian cancer ${ }^{(\mathbf{3})}$.

A meta-analysis from nine studies concluded that systematic lymphadenectomy might improve overall survival in advanced ovarian cancer ${ }^{(4)}$.

A recent retrospective review analyzing data from previous randomized 
trials demonstrated that a survival Benefit may be associated with lymphadenectomy in advanced ovarian cancer patients ${ }^{(5)}$.

However, other investigators have questioned the therapeutic efficacy of systematic lymphadenectomy ${ }^{(\boldsymbol{6})}$.

\section{AIM OF THE WORK}

The aim of this work is to review the surgical management of female patients with ovarian cancer including intraperitoneal complete cytoreduction and systematic lymphadenectomy to explain prognosis, postoperative morbidities, recurrence and follow up.

\section{PATIENTS AND METHODS}

After approval of the local ethics committee, informed consent forms were signed by all participants.

This study was conducted at Al Azhar university hospitals and El Agousa police hospital - Ministry of interior on 20 female patients suffered from different stages of epithelial ovarian cancer with the following inclusion criteria:

Patients with stage II, non-bulky stage III and only One patient with bilateral ovarian cancer stage Ic. Preoperative evaluation included patient's history, age, comorbidities and clinical pictures.

Patients were clinically examined in the laboratory by taking blood samples for a complete blood picture, liver and kidney function tests, blood sugar, coagulation profile and tumor marker CA-125. Moreover, Radiological investigations followed including chest X-ray, pelviabdominal Ultrasound, transvaginal Ultrasound, $\mathrm{CT}$ abdomen and pelvis with contrast. Additionally, PET-CT, MRI and Endoscopic examination were performed when indicated by clinical findings. considering:

Diagnosis of malignancy was done by

(1) Radiological criteria for suspicious malignancy: complex mass with solid component involving pelvic structure, enlarged pelvic and/or para-aortic lymph nodes, omental masses, peritoneal nodules. Metabolically highly active by PET-CT
(2) Findings of omental mass or ascetic fluid cytology biopsy.

(3) Findings of Intra-operative frozen section of the ovarian masses in patients with uncertain malignancy.

\section{Intra-operative method:}

Patients underwent surgical staging in form of total hysterectomy, bilateral salpingioopherectomy, omentectomy, aspiration of ascites, biopsy from peritoneal surface, maximal cytoreduction. Except one unmarried patient refuse panhysterectomy so fertility preserving surgery was done. Bilateral pelvic lymphadenectomy was done by removal of lymph nodes overlying and medial to external iliac and internal iliac vessels, from the obturator fossa anterior to the obturator nerve, and overlying the common iliac arteries. Aortic lymph node dissection was done by stripping the nodal tissue from the vena cava and aorta including aortocavl group to the level of the renal vessels crossing the origin of inferior mesenteric artery from the abdominal aorta.

\section{Pathological processing and follow up:}

All lymph nodes dissections and primary tumors were examined as in a routine histologic examination. Pathologic analysis of primary tumor included assessment of tumor type, stage and histologic grad. histopathologcal investigations and surgical staging were according to the International Federation of Gynecology and Obstetrics (FIGO) system with follow up period was for at least 6 months postoperative including: operative complications, prognosis and adjuvant chemotherapy.

\section{Statistical analysis}

Descriptive statistics were used to describe different characteristic of age, history, symptoms, signs, laboratory investigation, radiological findings, histopathology, staging, surgical procedures, prognosis and postoperative follow up.

\section{RESULTS}

The present study was conducted on female patients with ovarian cancer.

The study outcomes are as follows: 
Table (1): Distribution of studied patients according to age

\begin{tabular}{|c|c|}
\hline Age/year & No. $=\mathbf{2 0}$ \\
\hline Mean \pm SD & $51.35 \pm 8.16$ \\
Range & $37-64$ \\
\hline
\end{tabular}

This table shows that the mean age of the studied patients was 51.35 years ranging from 37-64 years.

Table (2): Distribution of studied patients according to clinical pictures

\begin{tabular}{|c|c|c|c|}
\hline Clinical picture & & No. & $\%$ \\
\hline \multirow{2}{*}{ Abdominal distention } & No & 9 & $45.0 \%$ \\
& Yes & 11 & $55.0 \%$ \\
\hline \multirow{2}{*}{ Abdominal pain } & No & 10 & $50.0 \%$ \\
& Yes & 10 & $50.0 \%$ \\
\hline \multirow{2}{*}{ Abdominal discomfort } & No & 12 & $60.0 \%$ \\
& Yes & 8 & $40.0 \%$ \\
\hline \multirow{2}{*}{ Abnormal bleeding } & No & 17 & $85.0 \%$ \\
& Yes & 3 & $15.0 \%$ \\
\hline \multirow{2}{*}{ Nonspecific GIT manifestation } & No & 7 & $35.0 \%$ \\
& Yes & 13 & $65.0 \%$ \\
\hline \multirow{2}{*}{ Urinary symptoms } & No & 16 & $80.0 \%$ \\
& Yes & 4 & $20.0 \%$ \\
\hline \multirow{2}{*}{ Back pain } & No & 18 & $90.0 \%$ \\
& Yes & 2 & $10.0 \%$ \\
\hline
\end{tabular}

This table shows that $55 \%$ of patients represented with abdominal distension, 50\% had abdominal pain, $40 \%$ abdominal discomfort, $15 \%$ had abnormal bleeding, $65 \%$ had nonspecific GIT manifestation, $20 \%$ had urinary symptoms and $10 \%$ had back pain.

Table (3): Distribution of studied patients according to radiological findings and $\mathrm{Ca} 125$ level

\begin{tabular}{|c|c|c|}
\hline \multicolumn{2}{|c|}{ Radiological findings } & No. = 20 \\
\hline \multirow{2}{*}{ Pelvic mass } & No & $0(0.0 \%)$ \\
& Yes & $20(100.0 \%)$ \\
\hline $\begin{array}{c}\text { Minimal to moderate } \\
\text { ascites }\end{array}$ & No & $14(70.0 \%)$ \\
Ymental nodules & No & $6(30.0 \%)$ \\
\hline \multirow{2}{*}{ Peritoneal nodule/s } & Yes & $8(60.0 \%)$ \\
& No & $15(75.0 \%)$ \\
\hline \multirow{2}{*}{ Yymph node } & No & $5(25.0 \%)$ \\
enlargement & Pelvic & $11(55.0 \%)$ \\
& Para-aortic & $3(10.0 \%)$ \\
& Pelvic and & $4(20.0 \%)$ \\
\hline \multicolumn{2}{|c|}{ Serum Ca125 levels } & No. = 20 \\
\hline \multirow{2}{*}{ CA 125 level (N. 35 u/ml) } & Mean & 625.5 \\
& Range & $17-3706$ \\
\hline
\end{tabular}

This table shows that all patients had pelvic mass, $30 \%$ had minimal to moderate ascites, $40 \%$ had omental nodules, $25 \%$ had peritoneal nodules

As regard lymph node enlargement 55\% had no enlarged lymph nodes, $20 \%$ had pelvic and paraaortic, $15 \%$ had paraaortic lymphadenopathy and $10 \%$ had pelvic lymphadenopathy Mean level of CA125 was 625.5 with range $17-3706$.

Table (4): Distribution of studied patients according to co-morbidities

\begin{tabular}{|c|c|c|c|}
\hline Co morbidities & No. & $\%$ \\
\hline \multirow{2}{*}{ D.M(Diabetes mellitus) } & No & 15 & $75.0 \%$ \\
& Yes & 5 & $25.0 \%$ \\
\hline \multirow{2}{*}{ HTN (Hypertension) } & No & 13 & $65.0 \%$ \\
& Yes & 7 & $35.0 \%$ \\
\hline \multirow{2}{*}{ Renal impairment } & No & 19 & $95.0 \%$ \\
& Yes & 1 & $5.0 \%$ \\
\hline \multirow{2}{*}{ HCV (hepatitis C virus) } & No & 17 & $85.0 \%$ \\
& Yes & 3 & $15.0 \%$ \\
\hline \multirow{2}{*}{ Asthmatic } & No & 19 & $95.0 \%$ \\
& Yes & 1 & $5.0 \%$ \\
\hline
\end{tabular}

This table shows that $25 \%$ of patients had D.M, 35\% had HTN, 5\% had renal impairment, $15 \%$ had $\mathrm{HCV}$ positive and $5 \%$ had bronchial asthma .

Table (5): Distribution of studied patients according to operations done

\begin{tabular}{|c|c|c|c|}
\hline \multicolumn{2}{|c|}{ Operation } & No. & $\%$ \\
\hline $\begin{array}{c}\text { THBSO (total } \\
\text { abdominal } \\
\text { hysterectomy and } \\
\text { bilateral salpingio- } \\
\text { oophorectomy) } \\
\end{array}$ & $\begin{array}{l}\text { No } \\
\text { Yes }\end{array}$ & 19 & $\begin{array}{l}5.0 \% \\
95.0 \%\end{array}$ \\
\hline Omentectomy & $\begin{array}{l}\text { No } \\
\text { Yes }\end{array}$ & \begin{tabular}{|c|}
0 \\
20 \\
\end{tabular} & $\begin{array}{c}0.0 \% \\
100.0 \%\end{array}$ \\
\hline Appendectomy & $\begin{array}{l}\text { No } \\
\text { Yes } \\
\end{array}$ & \begin{tabular}{|c|}
18 \\
2 \\
\end{tabular} & $\begin{array}{l}90.0 \% \\
10.0 \% \\
\end{array}$ \\
\hline Cholecystectomy & $\begin{array}{c}\text { No } \\
\text { Chronic calcular } \\
\text { cholycystitis }\end{array}$ & $\begin{array}{c}18 \\
2\end{array}$ & $\begin{array}{l}90.0 \% \\
10.0 \%\end{array}$ \\
\hline Peritentonectomy & $\begin{array}{c}\text { No } \\
\text { Right paracolic \& } \\
\text { right } \\
\text { subdiaphragmatic } \\
\text { Pelvic } \\
\text { peritonectomy }\end{array}$ & 18 & $\begin{array}{l}90.0 \% \\
5.0 \% \\
5.0 \%\end{array}$ \\
\hline Aspiration of ascites & $\begin{array}{l}\text { No } \\
\text { Yes }\end{array}$ & $\begin{array}{c}14 \\
6 \\
\end{array}$ & $\begin{array}{l}70.0 \% \\
30.0 \% \\
\end{array}$ \\
\hline Fertility preserving & $\begin{array}{l}\text { No } \\
\text { Yes }\end{array}$ & \begin{tabular}{|c|}
19 \\
1 \\
\end{tabular} & $\begin{array}{c}95.0 \% \\
5.0 \% \\
\end{array}$ \\
\hline Another procedures & $\begin{array}{c}\text { No } \\
\text { Excision of } \\
\text { peritoneal nodule } \\
\text { Falcifom ligament } \\
\text { excision }\end{array}$ & \begin{tabular}{|c|}
5 \\
4 \\
1
\end{tabular} & $\begin{array}{l}75.0 \% \\
20.0 \% \\
5.0 \%\end{array}$ \\
\hline
\end{tabular}


This table shows that $95 \%$ of patients undergo TAHBSO, all of patients had omentectomy, $10 \%$ had appendectomy, cholecystectomy, $30 \%$ had aspiration of ascities, $10 \%$ had peritonectomy in form of Right paracolic \& right subdiaphragmatic in $5 \%$ and pelvic pertonectomy in 5\%, 5\% had fertility preserving and $25 \%$ of cases had another procedure in form of excision of peritoneal nodules in $20 \%$ and $5 \%$ had falciform ligament excision

Table (6): Distribution of studied patients as regard operative and postoperative complications

\begin{tabular}{|c|c|c|c|}
\hline $\begin{array}{c}\text { Operative and post-operative } \\
\text { complication }\end{array}$ & & No. & $\%$ \\
\hline \multirow{2}{*}{ D.V.T } & No & 20 & $100 \%$ \\
\hline & Yes & 0 & $0 \%$ \\
\hline \multirow{2}{*}{$\begin{array}{l}\text { Renal dialysis (P.T. with renal } \\
\text { impairment) }\end{array}$} & No & 19 & $95 \%$ \\
\hline & Yes & 1 & $5 \%$ \\
\hline \multirow{2}{*}{$\begin{array}{l}\text { Right external iliac artery subacute } \\
\text { thrombus with significant stenosis } \\
\text { lead to lower limb ischemia } \\
\text { controlled by medical treatment }\end{array}$} & No & 19 & $95 \%$ \\
\hline & Yes & 1 & $5 \%$ \\
\hline \multirow{2}{*}{ Ureteric injury } & No & 19 & $95 \%$ \\
\hline & Yes & 1 & $5 \%$ \\
\hline \multirow{2}{*}{ Died (post dialysis) } & No & 19 & $95 \%$ \\
\hline & Yes & 1 & $5 \%$ \\
\hline \multirow{2}{*}{$\begin{array}{l}\text { Wound debridement \& secondary } \\
\text { suturing) }\end{array}$} & No & 18 & $90 \%$ \\
\hline & Yes & 2 & $10 \%$ \\
\hline \multirow{2}{*}{ Bladder injury } & No & 18 & $90 \%$ \\
\hline & Yes & 2 & $10 \%$ \\
\hline \multirow{2}{*}{ ICU admission } & No & 18 & $90 \%$ \\
\hline & Yes & 2 & $10 \%$ \\
\hline \multirow{2}{*}{ Incisional hernia } & No & 18 & $90 \%$ \\
\hline & Yes & 2 & $10 \%$ \\
\hline \multirow{2}{*}{ Lower limb oedema } & No & 16 & $80 \%$ \\
\hline & Yes & 4 & $20 \%$ \\
\hline \multirow{2}{*}{ Wound infection } & $\mathrm{No}$ & 15 & $75 \%$ \\
\hline & Yes & 5 & $25 \%$ \\
\hline \multirow{2}{*}{ Pelvic collection } & No & 15 & $75 \%$ \\
\hline & Yes & 5 & $25 \%$ \\
\hline \multirow{2}{*}{ Wound dehiscence } & No & 12 & $75 \%$ \\
\hline & Yes & 8 & $40 \%$ \\
\hline \multirow{2}{*}{ Blood transfusion } & $\mathrm{No}$ & 11 & $55 \%$ \\
\hline & Yes & 9 & $45 \%$ \\
\hline
\end{tabular}

This table shows that most common complication among studied patients was blood transfusion in $45 \%$ followed by wound dehiscence in $40 \%, 25 \%$ had wound infection and pelvic collection, $20 \%$ had lower limb edema, 10\% had ICU admission, bladder injury, incisional hernia and wound debridement with secondary suturing, 5\% had right external iliac artery subacute thrombus lead to lower limb ischemia, ureteric injury and only one patient (5\%) died post dialysis, no patient $(0 \%)$ suffered from DVT.

Table (7): Distribution of studied patients as regard pathology

\begin{tabular}{|c|c|c|c|}
\hline \multicolumn{2}{|c|}{ Pathology } & No. & $\%$ \\
\hline \multirow{3}{*}{ Laterality } & Right & 7 & $35.0 \%$ \\
& Left & 8 & $40.0 \%$ \\
& Bilatera & 5 & $25.0 \%$ \\
\hline \multirow{3}{*}{ Microscopic } & Serous carcinoma & 14 & $70.0 \%$ \\
(diagnosis) & Endometrioid & 3 & $15.0 \%$ \\
& carcinoma & & \\
& Mucinous carcinoma & 2 & $10.0 \%$ \\
& Clear cell carcinoma & 1 & $5.0 \%$ \\
\hline \multirow{2}{*}{ Grade } & 2 & 9 & $45.0 \%$ \\
& 3 & 11 & $55.0 \%$ \\
\hline Positive omental & No & 12 & $60.0 \%$ \\
nodules & Yes & 8 & $40.0 \%$ \\
\hline
\end{tabular}

This table shows that $40 \%$ of patients had left masses, 35\% right masses and 25\% bilateral, most common pathology was serous carcinoma in $70 \%$ followed by endometrioid carcinoma in $15 \%$, muscinous carcinoma in $10 \%$ and clear cell carcinoma in 5\%

Most of cases were grade 3 in 55\% and $45 \%$ was grade 2 with $40 \%$ of patients had positive omental nodules.

Table (8): Distribution of studied patients as regard criteria of lymph node dissected for 20 patients

\begin{tabular}{|c|c|c|c|c|}
\hline $\begin{array}{l}\text { lymph nodes } \\
\text { dissected }\end{array}$ & $\begin{array}{c}\text { Median } \\
\text { (IQR) }\end{array}$ & & No & $\%$ \\
\hline \multirow{2}{*}{$\begin{array}{c}\text { Total number } \\
\text { L.Ns }\end{array}$} & \multirow{2}{*}{$\begin{array}{c}30(26.5- \\
35)\end{array}$} & Total & 605 & \\
\hline & & Positive & 45 & $7.44 \%$ \\
\hline \multirow{2}{*}{$\begin{array}{l}\text { Paraaortic } \\
\text { L.Ns }\end{array}$} & \multirow{2}{*}{$\begin{array}{c}11(9- \\
13.5)\end{array}$} & Total & 229 & \\
\hline & & Positive & 16 & $6.99 \%$ \\
\hline \multirow{2}{*}{ Lt. pelvic L.Ns } & \multirow{2}{*}{$\begin{array}{c}10.0(8.5 \text { - } \\
11)\end{array}$} & Total & 188 & \\
\hline & & Positive & 17 & $9.04 \%$ \\
\hline \multirow{2}{*}{ Rt. Pelvic L.Ns } & \multirow{2}{*}{$\begin{array}{c}9.5(7.5- \\
11)\end{array}$} & Total & 188 & \\
\hline & & Positive & 12 & $6.38 \%$ \\
\hline \multirow{2}{*}{$\begin{array}{l}\text { Total pelvic } \\
\text { L.Ns }\end{array}$} & \multirow{2}{*}{$\begin{array}{l}19.5(17- \\
22)\end{array}$} & Total & 376 & \\
\hline & & Positive & 29 & $7.71 \%$ \\
\hline
\end{tabular}

This table shows that the total number of lymph node dissected was 605 , the median (IQR) was 30 (26.5 - 35), including 45(7.44\%) positive nodes.

Total para aortic L.Ns dissected was 229, the median (IQR) was 11 (9 - 13.5), including $16(6.99 \%)$ positive nodes in 5 patients.

Total Lt. pelvic L.Ns dissected was 188, the median (IQR) was $10.0(8.5-11)$, including $17(9.04 \%)$ positive nodes in 4 patients. 
Total Rt. pelvic L.Ns dissected was 188 , the median (IQR) was $9.5(7.5-11)$, including $12(6.38 \%)$ positive nodes in 3 patients.

Total pelvic L.Ns dissected was 376, the median (IQR) was 19.5 (17-22), including $29(7.71 \%)$ positive nodes.

Table (9): Distribution of studied patients as regard stages

\begin{tabular}{|l|c|c|}
\hline \multicolumn{2}{|c|}{} & No. = 20 \\
\hline \multirow{4}{*}{ Stage } & IIIa & $5(25.0 \%)$ \\
\cline { 2 - 3 } & IIb & $5(25.0 \%)$ \\
\cline { 2 - 3 } & IIIb & $6(30.0 \%)$ \\
\cline { 2 - 3 } & IC & $1(5.0 \%)$ \\
\cline { 2 - 3 } & IIIc & $3(15.0 \%)$ \\
\hline
\end{tabular}

The most of patients was stage IIIb in $30 \%$ followed by IIIa, IIb $25 \%$, IIIc in $15 \%$ and IC \% in $5 \%$.

Table (10): Distribution of studied patients as regard adjuvant chemotherapy

\begin{tabular}{|c|c|c|}
\hline \multicolumn{2}{|c|}{ Adjuvant chemotherapy } & $\begin{array}{c}\text { No. }= \\
20\end{array}$ \\
\hline Regemin & $\begin{array}{c}\text { Taxol/carboplatin/ } \\
\text { avastin } \\
\text { Taxol/carboplatin }\end{array}$ & $\begin{array}{c}2 \\
(10.5 \%) \\
17 \\
(89.5 \%)\end{array}$ \\
\hline Recurrences & $\begin{array}{c}\text { No } \\
\text { Local recurrence } \\
\text { Peritoneal nodule } \\
\text { Aorto-caval }\end{array}$ & $\begin{array}{c}16 \\
(84.2 \%) \\
1 \\
(5.3 \%) \\
1 \\
(5.3 \%) \\
1 \\
(5.3 \%)\end{array}$ \\
\hline $\begin{array}{l}\text { Total follow up time from } \\
\text { /-month) }\end{array}$ & $\begin{array}{c}\text { Mean } \pm \text { SD } \\
\text { Range }\end{array}$ & $\begin{array}{c}8.68 \pm \\
3.33 \\
6-20 \\
\end{array}$ \\
\hline
\end{tabular}

This table shows that $89.5 \%$ of patients received Taxol/carboplatin, $10.5 \%$ received Taxol/carboplatin/avastin.

$84.2 \%$ had no recurrence, $5.3 \%$ had local recurrence or peritoneal nodules or aortocaval recurrence. Mean follow up time was 8.68 months.

\section{DISCUSSION}

Ovarian cancer is the seventh cause of cancer death worldwide, and the sixth most common cancer in women. The disease is most often diagnosed at an advanced stage because there are no effective measures for early detection, and as a result, the long-term survival of patients with ovarian cancer ranges from $30 \%$ to $40 \%{ }^{(7)}$.

While long-term outcomes remain less than desirable, the survival of patients with advanced ovarian cancer has improved with the introduction of platinum and paclitaxel as standard front-line chemotherapy, and maximal cytoreductive surgery. The value of lymphadenectomy, however, in early and late stage ovarian cancer remains the subject of research ${ }^{(8)}$.

Although systematic lymphadenectomy has been shown to be feasible and safe in the treatment of advanced ovarian cancer, its therapeutic role remains controversial. The core issue of the controversy is whether removal of the lymph nodes should be performed only to stage the disease or whether removal improves survival. In the former case, lymph node regions at risk would only be sampled, whereas in the latter case there would be a systematic effort to remove all accessible lymph node-bearing tissue $^{(9)}$.

In the current study we aimed to review the surgical management of female patients with ovarian cancer including intraperitoneal complete cytoreduction and systematic lymphadenectomy to show prognosis, post operative morbidities, recurrence and follow up. 20 patients were involved with mean age of the studied patients was 51.35 years ranging from 37-64 years.

In a study by Chang et al. (10) 203 patients were included in the study The median age was 54 years (range 30-78 years) on other study by Iwase et al. (II) 124 patients were included with median age was 58 years (range, 29 to 83 years). With the same age range in Gasimli et al. ${ }^{(12)}$ study found that the median age at date of first diagnosis was 57 years (range 27$85)$.

In the current study we found that mean level of CA125 was 625.5 with range 17 - 3706 which was near to the level in a study by Chang et al. ${ }^{(10)}$ the median preoperative serum CA-125 level was $603.8 \mathrm{U} / \mathrm{mL}$ and lower than in Iwase et al. ${ }^{(11)}$ the median serum cancer antigen 125 (CA-125) level was $1,569.4 \mathrm{U} / \mathrm{mL}$ (range, 13.5 to $24,821 \mathrm{U} / \mathrm{mL}$ ) before NACT and $15.8 \mathrm{U} / \mathrm{mL}$ (range, 2.3 to $1,965.1 \mathrm{U} / \mathrm{mL}$ ) after NACT. Another study by Gasimli et al. ${ }^{(12)}$ found 
that the median serum concentration of CA125 was $576.5 \mathrm{U} / \mathrm{ml}$ (range 7-30,000).

In the present study we found that $25 \%$ of patients had D.M, $35 \%$ had HTN, $5 \%$ had renal impairment, $15 \%$ had HCV positive and 5\% had bronchial asthma, all patients had pelvic mass, $30 \%$ had minimal to moderate ascites, $40 \%$ had omental nodules, $25 \%$ had peritoneal nodules.

Gasimli et al. ${ }^{(12)}$ found that ascites was present in $69.3 \%$ of patients, with $40.4 \%$ of patients presenting with less than, and 28.9 $\%$ of patients presenting with more than, 500 $\mathrm{ml}$ of ascites. In $30.7 \%$ of patients, no ascites was present at all.

Moreover, we found that $95 \%$ of patients have undergone TAHBSO, all of patients had omentectomy, $10 \%$ had appendectomy, cholecystectomy, $30 \%$ had aspiration of ascities, $10 \%$ had peritonectomy in form of Right paracolic \& right subdiaphragmatic in $5 \%$ and pelvic pertonectomy in 5\%,5\% had fertility preserving and $25 \%$ of cases had another procedure in the form of excision of peritoneal nodules in $20 \%$ and $5 \%$ had falciform ligament excision.

Chang et al. (10) found that of 84 patients who underwent radical procedures, radical oophorectomy was performed in 72 patients $(85.7 \%)$, and 37 patients $(44.0 \%)$ had extensive upper abdominal surgery.

Iwase et al. (11) showed that exploratory laparotomy was performed in 11 patients, $\mathrm{TAH}+\mathrm{BSO}+\mathrm{OM}$ (minimum) in 10 patients, $\mathrm{TAH}+\mathrm{BSO}+\mathrm{OM}+$ excision of other organs (radical-1) such as the sigmoid colon, rectum, liver, and small intestine in 16 patients, $\mathrm{TAH}+\mathrm{BSO}+\mathrm{OM}+$ retroperitoneal lymphadenectomy (radical-2) in 38 patients, and $\mathrm{TAH}+\mathrm{BSO}+\mathrm{OM}+$ excision of other organs and retroperitoneal lymphadenectomy (radical$3)$ in 48 patients

In the present study we found that most common complication among studied patients was blood transfusion (45\%) followed by wound dehiscence (40\%).

Furthermore, $25 \%$ of the patients had wound infection and pelvic collection, 20\% had lower limb edema, $10 \%$ had ICU admission, bladder injury, incisional hernia and wound debridement with secondary suturing, 5\% had right external iliac artery subacute thrombus lead to lower limb ischemia, ureteric injury and only one patient $(5 \%)$ died post dialysis.

In comparison to other studies Chang et al. ${ }^{(10)}$ involved two groups with simple or radical surgery found that radical surgery had more complications in form of intraoperative and Postoperative blood transfusion in $\mathrm{n} 25 \%, 39.3 \%$ of patients respectively Infected lymphocyst in 12 patients, Wound infection in 6 patients, Intestinal obstruction in 4 patients, Thromboembolism, Anastomotic leakage, Ureteral injury, Sepsis in 3 patients and Intraabdominal abscess, Pneumothorax in 1 patients and Postoperative death $\backslash 30 \mathrm{~d}$ in 1 patients.

In the current study we found that $40 \%$ of patients had left masses, 35\% right masses and $25 \%$ bilateral, most common pathology was Serous adenocarcinoma in $70 \%$ followed by Endometrioid carcinoma in 15\%, Muscinous adenocarcinoma in $10 \%$, and Clear cell carcinoma in 5\%.

Regarding histologic subtypes in Iwase et al. ${ }^{(11)}$ study, serous adenocarcinoma accounted for $85.0 \%(105 / 124)$ of cases; furthermore, $92.7 \%(115 / 124)$ of cases if 10 cases with mixed adenocarcinoma and carcinosarcoma with serous components were included.

In consistent with our result Gasimli et al. ${ }^{(12)}$ found that the vast majority of patients $(93.6 \%)$ presented a serous histological subtype.

Moreover Cuylan et al. ${ }^{(13)}$ found that of 218 women who met the inclusion criteria, $64(29.4 \%)$ patients had endometrioid, 61 (28\%) had mucinous, 54 (24.8\%) had clear-cell and $39(17.9 \%)$ had mixed epithelial tumors and bilaterality in $49.1 \%$.

Most of cases in the current study were grade 3 in $55 \%$ and $45 \%$ was grade 2 with $40 \%$ of patients had positive omental nodules and $30 \%$ had abdominal peritonea metastasis

In consistent with our result Bachmann $\mathrm{C}$ et al include 108 patients and found that most of patients was grade 3 $(55.5 \%)$ and $(44.44 \%)$ were grade $\mathrm{G} 1 / 2$ (Bachmann C et al.,2016) also Gasimli et al. 
(12) found that most patients had grade III (70.6 $\%)$, followed by grade II ( $24.3 \%)$ and grade I $(5 \%)$.

In the current study we found that as regard lymph node enlargement 55\% had no enlarged lymph nodes, $20 \%$ had pelvic and paraaortic, $15 \%$ had paraaortic lymphadenopathy and $10 \%$ had pelvic lymphadenopathy, the median (IQR) of lymph nodes dissected from right pelvic was 9.5 (7.5 - 11), left pelvic was 10.00 (8.5 - 11), para aortic was $11(9-13.5)$ and the total (paraaortic and pelvic) was $30(26.5$ - 35)

Regarding dissected lymph node Iwase et al. (11) 86 patients underwent systematic retroperitoneal lymphadenectomy, and the mean number of dissected pelvic and para-aortic nodes was 46 (range, 19 to 96). Positive lymph nodes (LNs) were detected in 49 patients, including two patients for whom we only sampled bulky LNs. While negative LNs were detected 41 patients, also including two patients for whom we only sampled bulky LNs.

In another study by Cuylan et al. ${ }^{(13)}$ found that the median number of pelvic LNs removed and number of para-aortic LNs removed was 25 (10-93), 12 (5-66) respectively and $55.5 \%$ had retroperitoneal $\mathrm{LN}$ metastases, $64.7 \%$ had Peritoneal involvement and, $60.1 \%$ had Omental involvement.

In the current study we found that the most of patients was stage IIIb in $30 \%$ followed by IIIa, IIb $25 \%$, IIIc in $15 \%$ and IC $\%$ in $5 \%$.

This differ than other studies as in Chang et al. ${ }^{(10)}$ the majority of patients had FIGO stage IIIC disease (93.1\%) and serous histology $(82.3 \%)$ and in Iwase et al. ${ }^{(11)}$ six cases $(4.8 \%)$, stage IIIB; 77 cases $(62.1 \%)$, stage IIIC; and 41 cases (33.1\%), stage IV.

Another study by Cuylan et al. (13) found that there were 55 (25.2\%) women with stage IIIA1, $14(6.4 \%)$ with stage IIIA2, 34 $(15.6 \%)$ with stage IIIB and $115(52.8 \%)$ with stage IIIC disease.

In the current study after mean follow up time was 8.68 months $84.2 \%$ had no recurrence, $5.3 \%$ had local recurrence or peritoneal nodules or aorto caval recurrence.
On the other hand, Iwase et al. (11) study showed that Recurrence occurred in 91 of 113 patients, and irrespective of surgical procedure, recurrence rates were high, ranging from $75 \%$ to $94 \%$. Peritoneal dissemination was detected in about $62 \%$ of cases. LN recurrence was detected in $8 / 27$ patients (29.6\%) in the non-lymphadenectomy group (minimum and radical-1) and 17/86 patients $(19.8 \%)$ in the lymphadenectomy group (radical-2 and radical-3); this difference was not statistically significant $(\mathrm{p}=0.534)$.

Iwase et al. (11) found that median follow-up period was 39.5 months (range, 5 to 142 months). In Cuylan et al. ${ }^{(13)}$ the median duration of follow-up was 31.5 (range, 1-120) months.

The relative differences in results between this study and the other studies may be due to the smaller sample size, short follow up period, lack of follow up of patients, differences in surgical procedures, postoperative management, histopathological examination and different stages of disease.

\section{CONCLUSION:}

- Lymphadenectomy, as a routine treatment procedure in ovarian cancer, remains controversial. Moreover, systematic lymphadenectomy often prolongs operation times, which may result in additional surgical complications such as lymphocele, lymphatic obstruction, lymphocysts and lymphedema, however these complications may be alleviated, and better outcome occurred by proper intra operative and post operative management by expert gynecological oncologist involvement and leveraging adequate instruments, which can eventually improve survival.

- The surgical community should consider adopting the terms complete cytoreduction, optimal (for cases with $\mathrm{RD}<1 \mathrm{~cm}$ ) and suboptimal (residual $>1$ $\mathrm{cm}$ ) given the survival benefits of less than complete cytoreduction.

\section{REFERENCES}

1. Shih KK and Chi DS (2010): Maximal cytoreductive effort in epithelial ovarian 
cancer surgery. J. Gynecol. Oncol., 21: 75-80.

2. Kommoss S, Rochon J, Harter $\mathbf{P}$ et al. (2010): Prognostic impact of additional extended surgical procedures in advanced-stage primary ovarian cancer. Ann. Surg. Oncol., 17: 279-286.

3. Rouzier R, Bergzoll C, Brun JL et al. (2010): The role of lymph node resection in ovarian cancer: analysis of the Surveillance, Epidemiology, and End Results (SEER) database. BJOG., 117: 1451-1458.

4. Kim HS, Ju W, Jee BC et al. (2010): Systematic lymphadenectomy for survival in epithelial ovarian cancer: a meta analysis. Int. J. Gynecol. Cancer, 20: 520-528.

5. Du Bois A, Reuss A, Harter $P$ et al. (2010): Potential role of lymphadenectomy in advanced ovarian cancer: a combined exploratory analysis of three prospectively randomized phase III multicentre trials. J Clin Oncol., 28: 1733-1739.

6. Abe A, Furumoto H, Irahara $\mathrm{M}$ et al. (2010): The impact of systematic paraaortic and pelvic lymphadenectomy on survival in patients with optimally debulked ovarian cancer. J. Obstet. Gynaecol. Res., 36: 1023-1030.

7. Siegel R, Naishadham $D$ and Jemal A (2013): Cancer statistics, 2013. CA Cancer J. Clin., 63: 11-30.

8. Nick AM, Coleman RL, Ramirez PT et al. (2015): A framework for a personalized surgical approach to ovarian cancer. Nat. Rev. Clin. Oncol., 12: 239245.

9. Panici PB, Maggioni A, Hacker $\mathrm{N}$ et al. (2005): Systematic Aortic and Pelvic Lymphadenectomy versus Resection of Bulky Nodes Only in Optimally Debulked Advanced Ovarian

Cancer. https://www.ncbi.nlm.nih.gov/pubmed/158408 78

10. Chang SJ, Bristow RE and Ryu HS (2012): Impact of Complete Cytoreduction Leaving No Gross Residual Disease Associated with Radical Cytoreductive Surgical Procedures on Survival in Advanced Ovarian Cancer. Ann. Surg. Oncol., 19: 4059-4067.

11. Iwase $\mathrm{H}$, Takada $\mathrm{T}$, litsuka $\mathrm{C}$ et al. (2015): Clinical signifcance of systematic retroperitoneal lymphadenectomy during interval debulking surgery in advanced ovarian cancer patients. J. Gynecol. Oncol., 26(4): 303-310.

12. Gasimli K, Braicu E.I, Nassir M et al. (2016): Lymph Node Involvement Pattern and Survival Differences of FIGO IIIC and FIGO IIIA1 Ovarian Cancer Patients After Primary Complete Tumor Debulking Surgery: A 10-Year Retrospective Analysis of the Tumor Bank Ovarian Cancer Network. Ann. Surg. Oncol., 23: 1279.

13. Cuylan ZF, Meydanli MM, Sari ME et al. (2018): Prognostic factors for maximally or optimally cytoreduced stage III nonserous epithelial ovarian carcinoma treated with carboplatin/paclitaxel chemotherapy. J. Obstet. Gynaecol. Res., 44(7): 12841293. 